\title{
Gender-specific associations of vision and hearing impairments with adverse health outcomes in older Japanese: a population-based cohort study
}

\author{
Takehiro Michikawa*1, Yuji Nishiwaki*1, Yuriko Kikuchi' ${ }^{1}$, Makiko Nakano1, \\ Satoko Iwasawa1, Keiko Asakura'1, Ai Milojevic', Kunio Mizutari², \\ Hideyuki Saito $^{2}$, Susumu Ishida ${ }^{3}$, Tomonori Okamura ${ }^{4}$ and \\ Toru Takebayashi ${ }^{1}$
}

Address: ${ }^{1}$ Department of Preventive Medicine and Public Health, School of Medicine, Keio University, 35 Shinanomachi, Shinjuku-ku, Tokyo 160 8582, Japan, ${ }^{2}$ Department of Otorhinolaryngology, Head and Neck Surgery, School of Medicine, Keio University, 35 Shinanomachi, Shinjuku-ku, Tokyo 160-8582, Japan, ${ }^{3}$ Department of Ophthalmology, Hokkaido University Graduate School of Medicine, Kita 14, Nishi 5, Kita-ku, Sapporo 060-8648, Japan and ${ }^{4}$ Department of Preventive Cardiology, National Cardiovascular Center, 5-7-1 Fujishirodai, Suita, Osaka 565-8565, Japan

Email: Takehiro Michikawa* - di065051@sc.itc.keio.ac.jp; Yuji Nishiwaki* - nisiwaki@sc.itc.keio.ac.jp;

Yuriko Kikuchi - yurikikuhome@gmail.com; Makiko Nakano - di065011@sc.itc.keio.ac.jp; Satoko Iwasawa - iwasawa@sc.itc.keio.ac.jp; Keiko Asakura - jzf01334@nifty.com; Ai Milojevic - aishi@b-star.jp; Kunio Mizutari - tari@mbf.ocn.ne.jp;

Hideyuki Saito - hsaitorl@sc.itc.keio.ac.jp; Susumu Ishida - ishidasu@med.hokudai.ac.jp; Tomonori Okamura - okamurat@hsp.ncvc.go.jp; Toru Takebayashi - ttake@sc.itc.keio.ac.jp

* Corresponding authors

Published: 22 November 2009

BMC Geriatrics 2009, 9:50 doi:10.1186/147I-2318-9-50
Received: 20 May 2009

Accepted: 22 November 2009

This article is available from: http://www.biomedcentral.com/I47I-23I8/9/50

(c) 2009 Michikawa et al; licensee BioMed Central Ltd.

This is an Open Access article distributed under the terms of the Creative Commons Attribution License (http://creativecommons.org/licenses/by/2.0), which permits unrestricted use, distribution, and reproduction in any medium, provided the original work is properly cited.

\begin{abstract}
Background: Several epidemiological studies have shown that self-reported vision and hearing impairments are associated with adverse health outcomes (AHOs) in older populations; however, few studies have used objective sensory measurements or investigated the role of gender in this association. Therefore, we examined the association of vision and hearing impairments (as measured by objective methods) with AHOs (dependence in activities of daily living or death), and whether this association differed by gender.

Methods: From 2005 to 2006, a total of 80 I residents (337 men and 464 women) aged 65 years or older of Kurabuchi Town, Gunma, Japan, participated in a baseline examination that included vision and hearing assessments; they were followed up through September 2008. Vision impairment was defined as a corrected visual acuity of worse than 0.5 $(\log M A R=0.3)$ in the better eye, and hearing impairment was defined as a failure to hear a $30 \mathrm{~dB}$ hearing level signal at $\mathrm{I} \mathrm{kHz}$ in the better ear. Information on outcomes was obtained from the town hall and through face-to-face home visit interviews. We calculated the risk ratios (RRs) of AHOs for vision and hearing impairments according to gender.

Results: During a mean follow-up period of 3 years, 34 men (I0.1\%) and 52 women (II.3\%) had AHOs. In both genders, vision impairment was related to an elevated risk of AHOs (multi-adjusted RR for men and women together $=1.60,95 \%$ $\mathrm{Cl}=1.05-2.44$ ), with no statistically significant interaction between the genders. In contrast, a significant association between hearing impairment and AHOs (multi-adjusted $\mathrm{RR}=3.10,95 \% \mathrm{Cl}=1.43-6.72$ ) was found only in the men.

Conclusion: In this older Japanese population, sensory impairments were clearly associated with AHOs, and the association appeared to vary according to gender. Gender-specific associations between sensory impairments and AHOs warrant further investigation.
\end{abstract}




\section{Background}

It is not well known that adult-onset hearing loss and refractive errors (age-related causes of vision impairment) are respectively the world's highest- and second highestranking disabilities among people aged 60 years and over [1]. This lack of awareness means that sensory impairments have been largely dismissed as non-fatal, inevitable aspects of aging and have received minimal attention. There is growing evidence that self-reported vision and hearing impairments are associated with adverse health outcomes (AHOs) in older populations, and sensory impairments are likely to become an important public health issue [2-7]. To date, few studies have used objective vision and hearing examinations to investigate the association between sensory impairments and AHOs [8,9].

Evidence of gender differences has been reported regarding many aspects of health in older populations [10]. Women have a longer life expectancy than men in most countries, including Japan [11]. In contrast, women have a higher prevalence of co-morbid conditions than men $[12,13]$. All the evidence suggests the need for further research that pays attention to gender differences instead of treating gender as a confounder. To begin with, the prevalence of sensory impairments differs between men and women. Earlier studies showed that hearing impairment is more prevalent among men than among women, while women had a higher prevalence of vision impairment [14-16]. In addition, Appollonio et al. reported that in a cohort study in Italy the association of sensory impairments with mortality was gender-specific [17]. Thus, it is reasonable to assume that the association between sensory impairments and AHOs also differs according to gender. Even so, little research has been done on the question of gender differences.

With these points in mind, we tried to clarify the association of vision and hearing impairments (as measured by objective methods) with AHOs (dependence in activities of daily living [ADLs] or death), by analyzing 3-year follow-up data from a population-based cohort study of community-dwelling older Japanese. Our hypothesis was that the association would vary by gender.

\section{Methods \\ Study population}

The Kurabuchi study is an ongoing community-based longitudinal study of aging involving functional assessment of an older population in Kurabuchi Town, Takasaki City (approximately $100 \mathrm{~km}$ north of Tokyo, Japan) [18-20]. Between 2005 and 2006, public health nurses and local welfare commissioners visited home of residents aged 65 years or older and collected health information in face-toface interviews. We identified 1,294 non-institutionalized, functionally independent residents as eligible sub- jects. All of them were invited to participate in detailed health assessments at 8 community centers. Of the 1,294 eligible residents, 801 (337 men and 464 women; 62\%) took part in the detailed health assessments, and were followed for about 3 years until September 2008.

Comparisons between the participants and non-participants have been published previously [20]. In brief, the participants included a higher proportion of women and tended to be younger and better educated than the nonparticipants. On the other hand, there were no significant differences between the 2 groups in terms of difficulty reading a newspaper or hearing.

The Ethics Committee of the School of Medicine, Keio University (Tokyo, Japan) approved this study, and written informed consent was obtained from all participants.

\section{Sensory examinations at baseline}

Corrected distance $(5 \mathrm{~m})$ visual acuity, widely used in research into the association between vision impairment and AHOs $[8,9,17,21]$, was measured by trained technicians with a Landolt broken ring chart using an automatic visual analyzer (TOMEY NS-1100, Nagoya, Japan) under standard lighting conditions. We defined vision impairment as a corrected visual acuity of worse than 0.5 (logMAR $=0.3$ ) in the better eye, following the US criteria for visual impairment $[8,9]$. History of cataract surgery was also ascertained.

Pure-tone air-conduction audiometry was conducted in a separate quiet room by trained technicians with an audiometer (AA-56, RION Inc., Tokyo, Japan); subjects who used hearing aids were asked to remove them for the tests. To reduce the influence of ambient noise (24 to $29 \mathrm{~dB}$ sound pressure level $[\mathrm{A}]$ ), circumaural earphones were used. The audiometer was calibrated regularly to comply with Japanese standards. Due to the field setting nature of the study, we tested a signal with an intensity of $30 \mathrm{~dB}$ hearing level (HL) at a frequency of $1 \mathrm{kHz}$, and a signal with an intensity of $40 \mathrm{~dB} \mathrm{HL}$ at a frequency of $4 \mathrm{kHz}$, in accordance with Japan's Industrial Safety and Health Law's stipulations on health examinations for workers. Since daily conversation in Japanese relies more on lowfrequency signals than high-frequency signals [22], we defined hearing impairment as a failure to hear a $30 \mathrm{~dB}$ HL signal at $1 \mathrm{kHz}$ in the better ear [20]. We also obtained information on hearing aids usage.

\section{Covariates' information at baseline}

Body mass index (BMI) was calculated as weight $(\mathrm{kg})$ divided by the square of height $(\mathrm{m})$. Trained staffs measured blood pressure with an automatic sphygmomanometer in the right arm of seated participants after at least 15 minutes of rest. We defined hypertension as systolic blood 
pressure $\geq 140 \mathrm{mmHg}$ and/or diastolic blood pressure $\geq$ $90 \mathrm{mmHg}$ and/or use of antihypertensive agents. Nonfasting blood samples were taken for measurements of total cholesterol (enzymatic method), albumin (nephelometry method), hemoglobin $A_{1 c}$ (high-performance liquid chromatographic method), and C-reactive protein (latex turbidimetric immunoassay). Subjects were classified as having diabetes mellitus if it was self-reported and/ or they had a hemoglobin $\mathrm{A}_{1 \mathrm{c}}$ level $\geq 5.8 \%$. Information was also collected on the following: age; educational level (elementary or junior high school, high school or higher); marital status (married, single/divorced/widowed); smoking status (current smoker or not); alcohol consumption (current drinker or not); occupational noise exposure (yes, no); past/current history of major illness including stroke, coronary heart disease, cancer or Parkinson disease (summary of yes or no); and knee joint pain (yes, no). Additionally, we used well validated scales to evaluate the following 3 items as potential intermediate factors linking sensory impairments and AHOs: instrumental activities of daily living (IADLs) (Tokyo Metropolitan Institute of Gerontology Index of Competence [TMIG-IC], score 0-13)) [23]; depressive mode (Geriatric Depression Scale, 5-item version [GDS5], score 0-5) [24], and cognitive function (clock drawing test [CDT], score 0-4)) [25].

\section{Outcome measurements}

We defined AHOs [26] as either dependence in ADLs or death, i.e. the final form of functional transition [27]. Dependence in ADLs included nursing home admission or "long-term care" (LTC) eligibility, or impaired basic ADLs. LTC insurance was implemented by the Japanese government in 2000 to provide support according to the specific care needs of older people [28]. Those who want such support apply to their local town hall, where an initial assessment is made by computer of an 82-item questionnaire on physical and mental status. A board of medical and social services experts then uses this initial assessment, together with information provided by the assessor and attending doctor, to determine eligibility.

Information about death, nursing home admission, and LTC eligibility was obtained from the Kurabuchi Branch Office of Takasaki City Hall. To collect information about basic ADLs according to the Katz Index [29], repeat faceto-face home visit interviews were conducted twice (in 2007 and 2008). Participants were asked about their ability to perform the 6 basic ADL items (feeding, dressing, bathing, going to toilet, continence, and transferring [moving in and out of bed as well as in and out of chair]), and were given 3 response options: without help, with partial help, or with full help. We defined impaired basic ADLs as partial or full help needed to perform any of the 6 items.

\section{Statistical analysis}

All analyses were performed with STATA version 9 (STATA Corporation, College Station, Texas) after stratification by gender to test our hypothesis.

The chi-square test was used to compare the prevalence of baseline characteristics in relation to vision and hearing impairments. We used a Poisson regression with a robust error variance [30] to estimate risk ratios (RRs) and 95\% confidence intervals (CIs) as a measure of the relationship between vision/hearing impairments and AHOs. After calculation of crude RRs, a model mutually adjusted for vision and hearing impairments (Model 1) was applied. We then adjusted for age, educational level, marital status, smoking, alcohol consumption, past/current history of major illness and diabetes mellitus in addition to Model 1 (Model 2), since each of these variables changed the effect estimates by more than 10\% [31] in an age-adjusted model. By adding the omitted variables, including history of cataract surgery, to the final model one by one, we confirmed that they did not alter the effect estimates. We examined the statistical interaction between sensory impairments and gender with a likelihood ratio test. To evaluate reverse causation between sensory impairments and AHOs, we also calculated the RRs after excluding events occurring within the first 1 year of the study. We found no interaction between vision/hearing impairments on AHOs in this study.

IADLs, depressive mode and cognitive function were associated with AHOs in our study population. These three variables could be considered as intermediate factors linking sensory impairments and AHOs $[6,9,20,21,32]$. Therefore, RRs were compared between the genders with 3 additional models including respectively IADLs (TMIGIC score), depressive mode (GDS5 score), and cognitive function (CDT score).

\section{Results}

Of the 801 participants, we followed 796 (5 residents moved out of Kurabuchi) (follow-up proportion = $99.4 \%)$. During the 3-year follow-up period, 34 men (10.1\%) and 52 women (11.3\%) had AHOs (52 became dependent in ADLs and 34 died).

The baseline characteristics of the participants are grouped by gender and according to vision and hearing impairments in Table 1. Age distribution, educational level, IADLs, depressive mode and cognitive function tended to differ between the impaired and unimpaired groups, regardless of gender. There were no significant differences in the proportion of current smoker, elevated BMI, high total cholesterol level, low albumin level, or past/current history of major illness and diabetes between the 2 groups. 
Table I: Baseline characteristics (2005-2006) of the subjects according to gender and sensory impairments.

\begin{tabular}{|c|c|c|c|c|c|c|c|c|}
\hline \multirow[b]{2}{*}{ Variables } & \multicolumn{4}{|l|}{ Men } & \multicolumn{4}{|l|}{ Women } \\
\hline & $\begin{array}{r}\text { Vision im } \\
\text { No } \\
(n=275) \\
\text { Number }(\%)\end{array}$ & $\begin{array}{r}\text { airment } \\
\text { Impaired } \\
(n=60) \\
\text { Number }(\%)\end{array}$ & $\begin{array}{r}\text { Hearing in } \\
\text { No } \\
(n=271) \\
\text { Number }(\%)\end{array}$ & $\begin{array}{r}\text { pairment } \\
\text { Impaired } \\
(n=64) \\
\text { Number }(\%)\end{array}$ & $\begin{array}{r}\text { Vision im } \\
\text { No } \\
(\mathrm{n}=30 \mathrm{I}) \\
\text { Number (\%) }\end{array}$ & $\begin{array}{l}\text { airment } \\
\text { Impaired } \\
(\mathrm{n}=160) \\
\text { Number }(\%)\end{array}$ & $\begin{array}{r}\text { Hearing in } \\
\text { No } \\
(n=345) \\
\text { Number }(\%)\end{array}$ & $\begin{array}{l}\text { pairment } \\
\text { Impaired } \\
(n=116) \\
\text { Number }(\%)\end{array}$ \\
\hline $\begin{array}{l}\text { Age } \\
\text { (65-69 years) }\end{array}$ & $68(24.7)$ & $6(10.0)$ & $71(26.2)$ & $3(4.7)$ & $80(26.6)$ & $20(12.5)$ & $91(26.4)$ & $9(7.8)$ \\
\hline (70-79 years) & $152(55.3)$ & $32(53.3)$ & $152(56.1)$ & $32(50.0)$ & $163(54.2)$ & $80(50.0)$ & $190(55.1)$ & $53(45.7)$ \\
\hline (80- years) & $55(20.0)$ & $22(36.7)^{*}$ & 48 (I7.7) & $29(45.3)^{*}$ & $58(19.2)$ & $60(37.5)^{*}$ & $64(18.5)$ & $54(46.5)^{*}$ \\
\hline $\begin{array}{l}\text { Education } \\
\text { (high school or } \\
\text { higher) }\end{array}$ & $78(29.7)$ & $8(14.6)^{*}$ & $71(27.8)$ & $15(24.2)$ & $75(25.5)$ & $20(12.7)^{*}$ & $76(22.7)$ & $19(16.4)$ \\
\hline $\begin{array}{l}\text { Marital status } \\
\text { (married) }\end{array}$ & $221(84.7)$ & $46(83.6)$ & $216(85.0)$ & $51(82.3)$ & $179(61.5)$ & $83(52.9)$ & $204(61.3)$ & $58(50.4)^{*}$ \\
\hline $\begin{array}{l}\text { Current } \\
\text { smoker (yes) }\end{array}$ & $69(26.1)$ & $17(30.4)$ & $69(26.9)$ & $17(27.0)$ & $10(3.4)$ & $5(3.1)$ & II (3.3) & $4(3.5)$ \\
\hline $\begin{array}{l}\text { Current } \\
\text { alcohol drinker } \\
\text { (yes) }\end{array}$ & 149 (56.9) & $34(60.7)$ & $149(58.4)$ & $34(54.0)$ & $46(15.8)$ & I4 (8.9)* & $48(14.3)$ & $12(10.5)$ \\
\hline $\begin{array}{l}\text { Occupational } \\
\text { noise exposure } \\
\text { (yes) }\end{array}$ & $97(35.3)$ & $23(38.3)$ & $90(33.2)$ & $30(46.9)^{*}$ & $52(17.3)$ & $21(13.1)$ & $54(15.7)$ & $19(16.4)$ \\
\hline $\begin{array}{l}\text { Body mass } \\
\text { index }(<18.5 \\
\left.\mathrm{kg} / \mathrm{m}^{2}\right)\end{array}$ & I5 (5.5) & $5(8.3)$ & $18(6.6)$ & $2(3.1)$ & $28(9.3)$ & $14(8.8)$ & $36(10.4)$ & $6(5.2)$ \\
\hline$\left(\geq 25.0 \mathrm{~kg} / \mathrm{m}^{2}\right)$ & $77(28.0)$ & $8(13.3)$ & $72(26.6)$ & $13(20.3)$ & $83(27.6)$ & $35(21.9)$ & $84(24.4)$ & $34(29.3)$ \\
\hline $\begin{array}{l}\text { Total } \\
\text { cholesterol ( } \geq \\
5.7 \mathrm{mmol} / \mathrm{L})\end{array}$ & $45(16.4)$ & $12(20.3)$ & 48 (I7.7) & $9(14.3)$ & $125(4 \mid .5)$ & $59(36.9)$ & $|4|(40.9)$ & $43(37.1)$ \\
\hline $\begin{array}{l}\text { Albumin }(\leq 3.8 \\
\mathrm{g} / \mathrm{dl})\end{array}$ & $22(8.0)$ & $2(3.4)$ & $20(7.4)$ & $4(6.3)$ & $12(4.0)$ & $7(4.4)$ & II (3.2) & $8(6.9)$ \\
\hline $\begin{array}{l}\text { C-reactive } \\
\text { protein } \\
(>0.3 \mathrm{mg} / \mathrm{dl})\end{array}$ & $33(12.0)$ & $8(13.6)$ & $33(12.2)$ & $8(12.7)$ & $23(7.6)$ & $13(8.1)$ & $21(6.1)$ & $15(12.9)^{*}$ \\
\hline $\begin{array}{l}\text { Past/current } \\
\text { history of } \\
\text { major illness } \\
\text { (yes) }{ }^{\text {a }}\end{array}$ & $57(22.1)$ & $14(25.9)$ & $54(21.4)$ & $17(28.3)$ & $40(13.8)$ & $30(19.1)$ & $46(13.8)$ & $24(21.2)$ \\
\hline $\begin{array}{l}\text { Past/current } \\
\text { history of } \\
\text { hypertension } \\
\text { (yes) b }\end{array}$ & $169(63.5)$ & $33(60.0)$ & $168(64.6)$ & $34(55.7)$ & $197(66.6)$ & $116(73.0)$ & $225(66.2)$ & $88(76.5)^{*}$ \\
\hline $\begin{array}{l}\text { Past/current } \\
\text { history of } \\
\text { diabetes } \\
\text { mellitus (yes) c }\end{array}$ & $58(22.3)$ & $14(24.6)$ & $59(23.1)$ & $13(2 \mid .3)$ & $46(15.9)$ & $32(20.3)$ & $53(15.8)$ & $25(22.1)$ \\
\hline $\begin{array}{l}\text { Past/current } \\
\text { history of knee } \\
\text { joint pain (yes) }\end{array}$ & $85(31.0)$ & $28(46.7)^{*}$ & 81 (29.9) & $32(50.8) *$ & $129(42.9)$ & 7I (44.4) & $145(42.0)$ & $55(47.4)$ \\
\hline $\begin{array}{l}\text { History of } \\
\text { cataract } \\
\text { surgery (yes) }\end{array}$ & $41(14.9)$ & $8(13.3)$ & 37 (13.7) & $12(18.8)$ & $46(15.3)$ & $23(14.4)$ & $41(11.9)$ & $28(24.1)^{*}$ \\
\hline $\begin{array}{l}\text { Hearing aid } \\
\text { usage (yes) }\end{array}$ & $15(5.5)$ & $7(11.7)$ & $3(1.1)$ & $19(29.7)^{*}$ & $8(2.7)$ & $6(3.8)$ & $2(0.6)$ & $12(10.3)^{*}$ \\
\hline $\begin{array}{l}\text { Instrumental } \\
\text { activities of } \\
\text { daily living } \\
\text { (declined) }\end{array}$ & $22(8.4)$ & $14(25.5)^{*}$ & $27(10.6)$ & $9(14.5)$ & $21(7.3)$ & $39(24.7)^{*}$ & 37 (1 I.2) & $23(19.8)^{*}$ \\
\hline $\begin{array}{l}\text { Depressive } \\
\text { mode } \\
\text { (depressed) e }\end{array}$ & $61(22.5)$ & $17(28.3)$ & $54(20.2)$ & $24(38.1)^{*}$ & $75(25.3)$ & 75 (46.9)* & 101 (29.6) & $49(42.6)^{*}$ \\
\hline $\begin{array}{l}\text { Cognitive } \\
\text { function } \\
\text { (impaired) } f\end{array}$ & $9(3.3)$ & $12(20.0)^{*}$ & $14(5.2)$ & $7(10.9)$ & $5(1.7)$ & $16(10.1)^{*}$ & $12(3.5)$ & $9(7.8)$ \\
\hline
\end{tabular}

$* \mathrm{P}<.05$ by the chi-square test. aPast/current history of major illness contained stroke, coronary heart disease, cancer and Parkinson disease. bPast/current history of hypertension was defined as systolic blood pressure $\geq 140 \mathrm{mmHg}$ and/or diastolic blood pressure $\geq 90 \mathrm{mmHg}$ and/or use of antihypertensive agents. c Past/current history of diabetus mellitus was defined as self-reported and/or hemoglobin Alc $\geq 5.8 \%$. dDecline in instrumental activities of daily living defined as scoring $\leq 10$ in the Tokyo Metropolitan Institute of Gerontology Index of Competence. eDepressed defined as scoring $\geq 2$ in the Geriatric Depression

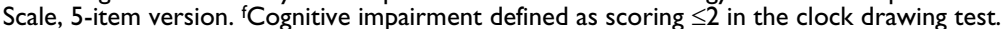


Table 2 shows the incidence and RRs of AHOs according to sensory impairments and gender. In both genders, vision impairment was related to an elevated risk of AHOs in both the crude analysis and in the vision and hearing mutually adjusted model. We observed no statistical evidence that the association between vision impairment and AHOs varied according to gender $(\mathrm{p}=.904$ in the likelihood ratio test). Therefore, we performed combinedgender analyses for vision impairment. After adjusting for gender, age, education, marital status, smoking, alcohol consumption, past/current history of major illness and diabetes, we found that vision impairment was associated with $\mathrm{AHOs}$ (RR for vision impairment $=1.60,95 \% \mathrm{CI}=$ 1.05-2.44). On the other hand, the men with impaired hearing were 3 times more likely to experience AHOs than those without (RR for hearing impairment $=3.10,95 \% \mathrm{CI}$ =1.43-6.72); no such increased risk was found among the women with impaired hearing. We found statistical evidence of interaction in the association of gender and hearing impairment with AHOs ( $\mathrm{p}=.006$ in the likelihood ratio test). Excluding events occurring within the first 1 year did not change the results substantially (data not shown).
As shown in Table 3, the RR for visual impairment in men was reduced by adjustment of three potential intermediate factors, while the RR in women remained little changed. With respect to hearing impairment, the RR in men was attenuated by $23 \%$ after adjusting for IADLs (RR $=2.39,95 \% \mathrm{CI}=1.04-5.52)$. Adjustment for depressive mode attenuated the $\mathrm{RR}$ somewhat $(\mathrm{RR}=2.72,95 \% \mathrm{CI}=$ 1.27-5.83), and for cognitive function only slightly $(\mathrm{RR}=$ $3.02,95 \% \mathrm{CI}=1.37-6.62)$.

In this population, 22 men (6.5\%) and 14 women (3.0\%) used hearing aids. Our findings were not altered substantially when we repeated all analyses after excluding these hearing aids users (data not shown).

\section{Discussion}

In this 3-year cohort study of an older Japanese population, vision and hearing impairments were associated with AHOs, and the association appeared to vary by gender. In both genders, vision impairment was related to an elevated risk of AHOs with no significant differences between men and women. In contrast, a clear association

Table 2: Risk ratios of adverse health outcomes (dependence in ADLs or death) for vision and hearing impairments by gender.

\begin{tabular}{|c|c|c|c|c|c|c|c|c|}
\hline & Incidence (\%) & $\begin{array}{l}\text { Crude } \\
\text { RR }(95 \% \mathrm{Cl})\end{array}$ & $P$-value & $\begin{array}{l}\text { Model I a } \\
\text { RR }(95 \% \text { Cl) }\end{array}$ & $P$-value & $\begin{array}{l}\text { Model } 2 \text { b } \\
\text { RR }(95 \% \text { Cl) }\end{array}$ & $P$-value & $P$ for interaction $\mathrm{c}$ \\
\hline \multicolumn{9}{|l|}{ Men } \\
\hline \multicolumn{9}{|c|}{ Vision impairment } \\
\hline No & 23/275 (8.4) & 1.00 & & 1.00 & & 1.00 & & \\
\hline Impaired & $11 / 60(18.3)$ & $\begin{array}{l}2.19 \\
(1.13-4.25)\end{array}$ & .020 & $\begin{array}{l}1.83 \\
(0.95-3.53)\end{array}$ & .071 & $1.43(0.63-3.26)$ & .393 & \\
\hline \multicolumn{9}{|l|}{$\begin{array}{l}\text { Hearing } \\
\text { impairment }\end{array}$} \\
\hline No & $|8 / 27|(6.6)$ & 1.00 & & 1.00 & & 1.00 & & \\
\hline Impaired & $16 / 64(25.0)$ & $\begin{array}{l}3.76 \\
(2.03-6.97)\end{array}$ & $<.001$ & $\begin{array}{l}3.49 \\
(1.86-6.53)\end{array}$ & $<.001$ & $3.10(1.43-6.72)$ & .004 & \\
\hline \multicolumn{9}{|l|}{ Women } \\
\hline \multicolumn{9}{|c|}{ Vision impairment } \\
\hline No & $23 / 301(7.6)$ & 1.00 & & 1.00 & & 1.00 & & \\
\hline Impaired & $29 / 160(18.1)$ & $\begin{array}{l}2.37 \\
(1.42-3.96)\end{array}$ & .001 & $\begin{array}{l}2.28 \\
(1.35-3.83)\end{array}$ & .002 & $\begin{array}{l}1.60 \\
(0.97-2.63)\end{array}$ & .064 & \\
\hline \multicolumn{9}{|l|}{$\begin{array}{l}\text { Hearing } \\
\text { impairment }\end{array}$} \\
\hline No & $34 / 345$ (9.9) & 1.00 & & 1.00 & & 1.00 & & \\
\hline Impaired & $18 / 116(15.5)$ & $\begin{array}{l}1.57 \\
(0.93-2.68)\end{array}$ & .094 & $\begin{array}{l}1.40 \\
(0.82-2.39)\end{array}$ & .216 & $\begin{array}{l}0.71 \\
(0.38-1.31)\end{array}$ & .269 & \\
\hline \multicolumn{9}{|c|}{ Men and Women } \\
\hline \multicolumn{9}{|c|}{ Vision impairment } \\
\hline No & $46 / 576(8.0)$ & 1.00 & & 1.00 & & 1.00 & & \\
\hline Impaired & $40 / 220(18.2)$ & $\begin{array}{l}2.28 \\
(1.53-3.38)\end{array}$ & $<.001$ & $\begin{array}{l}2.07 \\
(1.38-3.09)\end{array}$ & $<.001$ & $\begin{array}{l}1.60 \\
(1.05-2.44)\end{array}$ & .028 & .904 \\
\hline \multicolumn{9}{|l|}{$\begin{array}{l}\text { Hearing } \\
\text { impairment }\end{array}$} \\
\hline No & $52 / 616(8.4)$ & 1.00 & & 1.00 & & 1.00 & & \\
\hline Impaired & $34 / 180(18.9)$ & $\begin{array}{l}2.24 \\
(1.50-3.34)\end{array}$ & $<.001$ & $\begin{array}{l}2.00 \\
(1.33-3.01)\end{array}$ & .001 & $\begin{array}{l}1.23 \\
(0.76-1.97)\end{array}$ & .396 & .006 \\
\hline
\end{tabular}

RR: risk ratio, $\mathrm{Cl}$ : confidence interval. a Variables included in the model I were vision and hearing impairments. bln addition to the model I, age (continuous), education, marital status, smoking, alcohol consumption, past/current history of major illness and diabetes mellitus were included. For combined-gender analysis, we further adjusted for gender. cStatistical interaction between sensory impairments and gender with a likelihood ratio test. 
between hearing impairment and AHOs was found only in the men.

The gender-specific differences observed in this study are not particularly surprising, since earlier studies have suggested gender differences in the association between sensory impairments and AHOs. In a study of the relationship between hearing impairment (assessed by the whispered voice test) and reduced survival, an association was observed in men but not in women [17]. As for the relationship between hearing impairment with AHOs, the National Health Interview Survey in the United States showed similar results to ours: self- or proxy-reported hearing impairment was an independent predictor of mortality for African American men, but not for women [33]. Another study that targeted only women showed that vision impairment (best corrected vision worse than 20/40) was related to functional decline, while hearing impairment (unable to hear $40 \mathrm{~dB}$ HL at $2 \mathrm{kHz}$ in the better ear) was not [9]. These early studies support the results of our study, but it should be noted that assessment of gender differences was not their main objective.

The gender differences found in our study can be partially explained by the gender-specific social roles and characteristics typical of older Japanese. Retired Japanese men tend to withdraw from social activities [34], and hearing impairment may exacerbate their feelings of loneliness and estrangement from society. In contrast, most Japanese women of this generation are housewives whose everyday lives have been embedded in the local community from an early age [35]: their involvement in the local community may minimize the influence of communication problems caused by hearing impairment. On the other hand, vision impairment would greatly hinder the performance of housework, which would have a greater negative impact on the well-being of women, who usually do most of the housework. Our findings cannot, therefore, be generalized to other populations without further epidemiological research.

The potential mechanism by which gender-specific sensory impairments lead to AHOs can be analyzed according to the 3 earlier reported potential pathways [32]: 1) underlying conditions and risk factors such as smoking, alcohol consumption, obesity, hypertension and diabetes mellitus [36-40], which affect both sensory function and outcome; 2 ) a direct effect of sensory impairments on outcome; 3 ) an indirect effect of sensory impairments on outcome through some intermediate factors. As for the first pathway, we observed an attenuation of RR for sensory impairments after adjusting for underlying conditions and risk factors, indicating that this pathway is a valid factor in our results. To differentiate the second and the third pathways, IADLs, depression and cognitive function, which are all associated with sensory impairments

Table 3: Associations of vision and hearing impairments with adverse health outcomes (dependence in ADLs or death) through three potential intermediate factors by gender.

\begin{tabular}{|c|c|c|c|c|c|c|c|}
\hline & $\begin{array}{l}\text { Model } 2 \text { a } \\
\text { RR }(95 \% \mathrm{Cl})\end{array}$ & $\begin{array}{l}\text { Model } 2+\text { Instrumental } \\
\text { activities of daily living b } \\
\text { RR }(95 \% \mathrm{Cl})\end{array}$ & $P$-value & $\begin{array}{l}\text { Model } 2+\text { depres- } \\
\text { sive mode c } \\
\text { RR }(95 \%) \mathrm{Cl})\end{array}$ & $P$-value & $\begin{array}{l}\text { Model } 2+\text { cognitive } \\
\text { function d } \\
\text { RR }(95 \% \mathrm{Cl})\end{array}$ & $P$-value \\
\hline \multicolumn{8}{|l|}{ Men } \\
\hline \multicolumn{8}{|l|}{$\begin{array}{l}\text { Vision } \\
\text { impairment }\end{array}$} \\
\hline No & 1.00 & 1.00 & & 1.00 & & 1.00 & \\
\hline Impaired & $\begin{array}{l}1.43 \\
(0.633 .26)\end{array}$ & $\begin{array}{l}0.73 \\
(0.242 .21)\end{array}$ & .578 & $\begin{array}{l}1.20 \\
(0.532 .71)\end{array}$ & .657 & $\begin{array}{l}1.12 \\
(0.502 .52)\end{array}$ & .784 \\
\hline \multicolumn{8}{|l|}{$\begin{array}{l}\text { Hearing } \\
\text { impairment }\end{array}$} \\
\hline No & 1.00 & 1.00 & & 1.00 & & 1.00 & \\
\hline Impaired & $\begin{array}{l}3.10 \\
(1.436 .72)\end{array}$ & $\begin{array}{l}2.39 \\
(1.045 .52)\end{array}$ & .041 & $\begin{array}{l}2.72 \\
(1.275 .83)\end{array}$ & .010 & $\begin{array}{l}3.02 \\
(1.376 .62)\end{array}$ & .006 \\
\hline \multicolumn{8}{|l|}{ Women } \\
\hline \multicolumn{8}{|l|}{$\begin{array}{l}\text { Vision } \\
\text { impairment }\end{array}$} \\
\hline No & 1.00 & 1.00 & & 1.00 & & 1.00 & \\
\hline Impaired & $\begin{array}{l}1.60 \\
(0.972 .63)\end{array}$ & $\begin{array}{l}1.56 \\
(0.912 .65)\end{array}$ & .103 & $\begin{array}{l}1.55 \\
(0.892 .68)\end{array}$ & .119 & $\begin{array}{l}1.60 \\
(0.972 .63)\end{array}$ & .065 \\
\hline \multicolumn{8}{|l|}{$\begin{array}{l}\text { Hearing } \\
\text { impairment }\end{array}$} \\
\hline No & 1.00 & 1.00 & & 1.00 & & 1.00 & \\
\hline Impaired & $\begin{array}{l}0.71 \\
(0.38 \quad 1.31)\end{array}$ & $\begin{array}{l}0.75 \\
(0.40 \quad 1.39)\end{array}$ & .359 & $\begin{array}{l}0.71 \\
(0.37 \quad 1.34)\end{array}$ & .290 & $\begin{array}{l}0.70 \\
(0.38 \quad 1.29)\end{array}$ & .249 \\
\hline
\end{tabular}

RR: risk ratio, Cl: confidence interval. aVariables included in the model 2 were vision and hearing impairments, age (continuous), education, marital status, smoking, alcohol consumption, past/current history of major illness and diabetes mellitus. bTokyo Metropolitan Institute of Gerontology Index of

Competence (score 0-13). ' Geriatric Depression Scale, 5-item version (score 0-5). ${ }^{d}$ Clock drawing test (score 0-4). 
$[6,9,20,21,32]$, were adjusted for as potential intermediate factors. In men, the RR for hearing impairment was reduced by $23 \%$ and $12 \%$ after adjusting for IADLs and depressive mode, respectively. Thus, the relationship between hearing impairment and AHOs can be partially explained by this indirect pathway. After adjusting for the 3 potential intermediate factors, the RR for vision impairment in men was attenuated, but in women it remained unchanged. Vision impairment has been reported to be associated with increased risk of falls, hip fracture [41] and unintentional injury mortality [42]. Osteoporosis, a risk factor for hip fracture, is more prevalent in women than in men [13]. Thus, the pathway explaining the relationship between vision impairment and AHOs may vary between the genders. This issue needs to be addressed in future research involving large sample populations.

Our findings suggest that effective care of older adults with sensory impairments is important. Considering the high prevalence of hearing impairment in older populations $[36,37]$, strategies to fight it are an important public health issue. Since recent evidence suggests that lifestyle factors such as smoking and chronic conditions such as hypertension and diabetes mellitus play a key role in the progression of age-related hearing loss [36-38,40,43], measures to address these issues should be begun in early adulthood. Proper use of technology can also minimize the impact of hearing impairment on quality of life [4]. The number of people with hearing impairment who use hearing aids is relatively small [14], so the simple promotion of hearing aid use could be a meaningful strategy in improving the well-being of older adults. With respect to vision, methods of preventing or delaying vision impairment already exist for the 5 major causes (uncorrected refractive error, cataract, glaucoma, diabetic retinopathy and macular degeneration) $[39,44]$. However, figures from the United Kingdom indicate that only $58.4 \%$ of adults aged 50 or older with vision problems actually receive quality care [45]. Consequently, efforts to educate people on the importance of seeking care for sensory impairments are indispensable. Our results also suggest that care related to sensory impairments should be targeted differently for men and women.

We were able to follow $99.4 \%$ of the subjects, so there is little possibility of selection bias caused by loss to followup. We also included a wide range of adverse healthrelated events as outcome items, and considered various covariates either as confounding factors or intermediate factors in AHOs. Moreover, studies using objective sensory measurements instead of subjects' self-reporting are very limited $[8,9]$. The limitation of this study, however, was that single examination on exposure might have underestimated the true association between sensory impairments and AHOs due to regression dilution effects.
In addition, because of the small sample size, it was difficult to examine the relationships between sensory impairments and individual outcome (dependence in ADLs and death) and to exclude the possibility that the gender-specific associations between sensory impairments and AHOs were due to chance alone.

\section{Conclusion}

This present study not only indicated a clear association between sensory impairments as measured by objective methods and AHOs in community-dwelling Japanese older adults, but also suggested the possibility of gender differences in the association. Gender-specific associations between sensory impairments and AHOs warrant further investigation.

\section{Competing interests}

The authors declare that they have no competing interests.

\section{Authors' contributions}

TM, YN and TT participated in the study design, data collection, analysis and interpretation of data, and writing of the article. YK, MN, SI, KA and AM participated in data collection and interpretation of data, and reviewed drafts of the article. KM, HS and SI participated in the study design as an otorhinolaryngologist or ophthalmologist, and reviewed drafts of the article. TO supervised data analysis and interpretation, and contributed to preparation of the article. All authors read and approved the final version of the article.

\section{Acknowledgements}

We thank all staff members of the Kurabuchi study group and the municipal government for their cooperation. In addition, the authors would like to thank Michiko Okamoto, Yoko Osabe, Masako Totsuka, Eriko Matsumura and Shinobu Matsuda for their valuable help on field management.

This study was supported by a grant-in-aid from the Ministry of Education, Culture, Sports, Science and Technology, Japan (No. 19390166).

\section{References}

I. World Health Organization: Global burden of disease. Part 3: Disease incidence, prevalence and disability. Geneva: WHO; 2008.

2. Laforge RG, Spector WD, Sternberg J: The relationship of vision and hearing impairment to one-year mortality and functional decline. J Aging Health 1992, 4: I26-I48.

3. Rudberg MA, Furner SE, Dunn JE, Cassel CK: The relationship of visual and hearing impairments to disability: an analysis using the longitudinal study of aging. J Gerontol 1993, 48:M26I-265.

4. Wallhagen MI, Strawbridge WJ, Shema SJ, Kurata J, Kaplan GA: Comparative impact of hearing and vision impairment on subsequent functioning. J Am Geriatr Soc 200I, 49: I086-I092.

5. Raina $P$, Wong $M$, Massfeller $H$ : The relationship between sensory impairment and functional independence among elderly. BMC Geriatr 2004, 4:3.

6. Crews JE, Campbell VA: Vision impairment and hearing loss among community-dwelling older Americans: implications for health and functioning. Am J Public Health 2004, 94:823-829.

7. Spiers NA, Matthews RJ, Jagger C, Matthews FE, Boult C, Robinson TG, Brayne C: Diseases and impairments as risk factors for 
onset of disability in the older population in England and Wales: findings from the Medical Research Council Cognitive Function and Ageing Study. J Gerontol A Biol Sci Med Sci 2005 , 60:248-254.

8. Reuben DB, Mui S, Damesyn M, Moore AA, Greendale GA: The prognostic value of sensory impairment in older persons. J Am Geriatr Soc 1999, 47:930-935.

9. Lin MY, Gutierrez PR, Stone KL, Yaffe K, Ensrud KE, Fink HA, Sarkisian CA, Coleman AL, Mangione CM: Vision impairment and combined vision and hearing impairment predict cognitive and functional decline in older women. J Am Geriatr Soc 2004, 52:1996-2002

10. Oksuzyan A, Juel K, Vaupel JW, Christensen K: Men: good health and high mortality. Sex differences in health and aging. Aging Clin Exp Res 2008, 20:91-102.

II. World Health Organization: The world health report 2004 changing history. Geneva: WHO; 2004.

12. Ng TP, Niti M, Chiam PC, Kua EH: Prevalence and correlates of functional disability in multiethnic elderly Singaporeans. J Am Geriatr Soc 2006, 54:21-29.

13. Murtagh KN, Hubert HB: Gender differences in physical disability among an elderly cohort. Am J Public Health 2004 94:|406-|4||.

14. Smeeth L, Fletcher AE, Ng ES, Stirling S, Nunes M, Breeze E, Bulpitt C], Jones D, Tulloch A: Reduced hearing, ownership, and use of hearing aids in elderly people in the UK--the MRC Trial of the Assessment and Management of Older People in the Community: a cross-sectional survey. Lancet 2002, 359: $1466-1470$

15. Evans JR, Fletcher AE, Wormald RP, Ng ES, Stirling S, Smeeth L, Breeze E, Bulpitt C], Nunes M, Jones D, et al.: Prevalence of visual impairment in people aged 75 years and older in Britain: results from the MRC trial of assessment and management of older people in the community. $\mathrm{Br}$ J Ophthalmol 2002, 86:795-800.

16. Caban AJ, Lee DJ, Gómez-Marín O, Lam BL, Zheng DD: Prevalence of concurrent hearing and visual impairment in US adults: The National Health Interview Survey, 1997-2002. Am J Public Health 2005, 95: 1940-1942.

17. Appollonio I, Carabellese C, Magni E, Frattola L, Trabucchi M: Sensory impairments and mortality in an elderly community population: a six-year follow-up study. Age Ageing 1995 24:30-36.

18. Asakura K, Nishiwaki Y, Milojevic A, Michikawa T, Kikuchi Y, Nakano M, Iwasawa S, Hillebrand G, Miyamoto K, Ono M, et al.: The association of lifestyle factors with visible skin aging in older Japanese men and women. J Epidemiol 2009, 19:251-259.

19. Michikawa T, Ishida S, Nishiwaki Y, Kikuchi Y, Tsuboi T, Hosoda K, Ishigami A, Iwasawa S, Nakano M, Takebayashi T: Serum antioxidants and age-related macular degeneration among older Japanese. Asia Pac J Clin Nutr 2009, 18:1-7.

20. Harada S, Nishiwaki Y, Michikawa T, Kikuchi Y, Iwasawa S, Nakano M, Ishigami A, Saito H, Takebayashi T: Gender difference in the relationships between vision and hearing impairments and negative well-being. Prev Med 2008, 47:433-437.

2I. Evans JR, Smeeth L, Fletcher AE: Risk of admission to a nursing home among older people with visual impairment in Great Britain. Arch Ophthalmol 2008, I 26: | 428-|433.

22. Okamoto M, Nakanishi N, Tatara K: Self-reported hearing difficulty and hearing impairment in Japanese people living in a community. Int J Audiol 2004, 43:54-59.

23. Koyano W, Shibata H, Nakazato K, Haga H, Suyama Y: Measurement of competence: reliability and validity of the TMIG Index of Competence. Arch Gerontol Geriatr 1991, 13:103-116.

24. Hoyl MT, Alessi CA, Harker JO, Josephson KR, Pietruszka FM, KoeIfgen M, Mervis JR, Fitten LJ, Rubenstein LZ: Development and testing of a five-item version of the Geriatric Depression Scale. J Am Geriatr Soc 1999, 47:873-878.

25. Nishiwaki Y, Breeze E, Smeeth L, Bulpitt C], Peters R, Fletcher AE: Validity of the Clock-Drawing Test as a screening tool for cognitive impairment in the elderly. Am J Epidemiol 2004, 160:797-807.

26. McCusker J, Bellavance F, Cardin S, Trépanier S, Verdon J, Ardman O Detection of older people at increased risk of adverse health outcomes after an emergency visit: the ISAR screening tool. J Am Geriatr Soc 1999, 47:1229-1237.
27. Manton KG: A longitudinal study of functional change and mortality in the United States. J Gerontol 1988, 43:SI53-161.

28. Tsutsui T, Muramatsu N: Japan's universal long-term care system reform of 2005: containing costs and realizing a vision. J Am Geriatr Soc 2007, 55: I458-I 463.

29. Katz S, Ford AB, Moskowitz RW, Jackson BA, Jaffe MW: Studies of Illness in the Aged. The Index of ADL: A Standardized Measure of Biological and Psychosocial Function. JAMA 1963, 185:914-919.

30. Zou G: A modified poisson regression approach to prospective studies with binary data. Am J Epidemiol 2004, 159:702-706.

31. Greenland S: Modeling and variable selection in epidemiologic analysis. Am J Public Health 1989, 79:340-349.

32. Guralnik JM: The impact of vision and hearing impairments on health in old age. J Am Geriatr Soc 1999, 47: 1029-1031.

33. Lam BL, Lee DJ, Gómez-Marín O, Zheng DD, Caban AJ: Concurrent visual and hearing impairment and risk of mortality: the National Health Interview Survey. Arch Ophthalmol 2006, I24:95-10।

34. Takahashi M, Shibazaki S, Nagai M: Characteristics of social activity of the elderly who belong to senior citizens. Nippon Koshu Eisei Zasshi 2003, 50:970-979. (in Japanese with English abstract)

35. Okamoto $\mathrm{H}$ : Effects of social activities on life satisfaction among the elderly: four aspects in men and women. Nippon Koshu Eisei Zasshi 2008, 55:388-395. (in Japanese with English abstract)

36. Helzner EP, Cauley JA, Pratt SR, Wisniewski SR, Zmuda JM, Talbott EO, de Rekeneire N, Harris TB, Rubin SM, Simonsick EM, et al: Race and sex differences in age-related hearing loss: the Health, Aging and Body Composition Study. J Am Geriatr Soc 2005, 53:2119-2127.

37. Cruickshanks KJ, Klein R, Klein BE, Wiley TL, Nondahl DM, Tweed TS: Cigarette smoking and hearing loss: the epidemiology of hearing loss study. JAMA 1998, 279:1715-1719.

38. Agrawal Y, Platz EA, Niparko JK: Prevalence of hearing loss and differences by demographic characteristics among US adults: data from the National Health and Nutrition Examination Survey, 1999-2004. Arch Intern Med 2008, 168:I522-I530.

39. Gohdes DM, Balamurugan A, Larsen BA, Maylahn C: Age-related eye diseases: an emerging challenge for public health professionals. Prev Chronic Dis 2005, 2:AI7.

40. Fransen E, Topsakal V, Hendrickx JJ, Van Laer L, Huyghe JR, Van Eyken E, Lemkens N, Hannula S, Mäki-Torkko E, Jensen M, et al.: Occupational noise, smoking, and a high body mass index are risk factors for age-related hearing impairment and moderate alcohol consumption is protective: a European populationbased multicenter study. J Assoc Res Otolaryngol 2008, 9:264-276.

4I. Klein BE, Klein R, Lee KE, Cruickshanks KJ: Performance-based and self-assessed measures of visual function as related to history of falls, hip fractures, and measured gait time. The Beaver Dam Eye Study. Ophthalmology 1998, 105:160-164.

42. Lee DJ, Gómez-Marín O, Lam BL, Zheng DD: Visual impairment and unintentional injury mortality: the National Health Interview Survey 1986-1994. Am J Ophthalmol 2003, 136: II52-II54.

43. Rosen S, Bergman M, Plester D, El-Mofty A, Satti MH: Presbycusis study of a relatively noise-free population in the Sudan. Ann Otol Rhinol Laryngol 1962, 71:727-743.

44. Rowe $\mathrm{S}$, MacLean $\mathrm{CH}$ : Quality indicators for the care of vision impairment in vulnerable elders. J Am Geriatr Soc 2007, 55:S450-456.

45. Steel N, Bachmann M, Maisey S, Shekelle P, Breeze E, Marmot M, Melzer D: Self reported receipt of care consistent with 32 quality indicators: national population survey of adults aged 50 or more in England. BMJ 2008, 337:a957.

\section{Pre-publication history}

The pre-publication history for this paper can be accessed here:

http://www.biomedcentral.com/1471-2318/9/50/prepub 